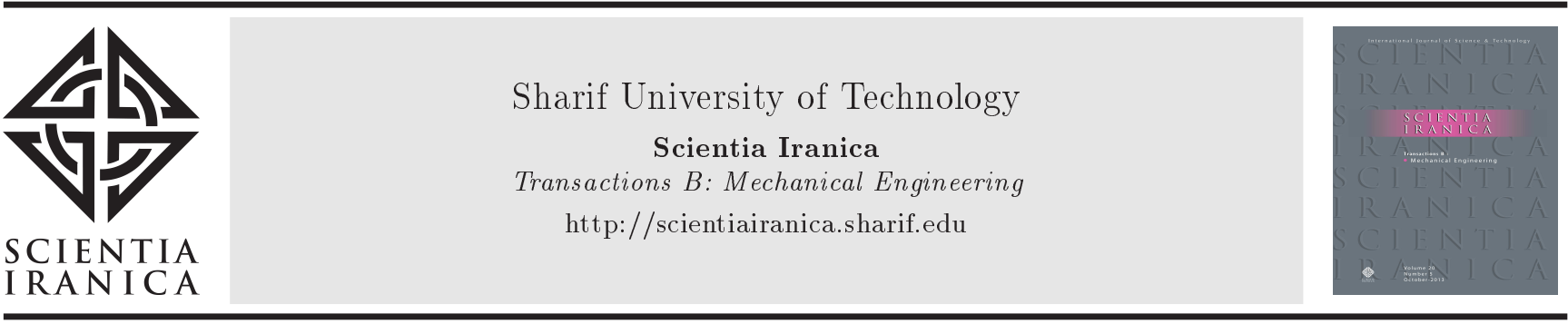

\title{
Experimental investigation of magnetic abrasive polishing of paramagnetic workpieces
}

\author{
S.M. Safavi, S. Hasanvand, and R. Jafari Nedoushan* \\ Department of Mechanical Engineering, Isfahan University of Technology, Isfahan, 84156-83111, Iran.
}

Received 30 August 2016; received in revised form 10 October 2017; accepted 9 April 2018

\author{
KEYWORDS \\ Magnetic abrasive \\ finishing; \\ Paramagnetic alloys \\ deburring; \\ Rotational speed of \\ abrasive pins; \\ Abrasive pins \\ characteristics; \\ Abrasive pins \\ quantity.
}

\begin{abstract}
This study investigates the application of the magnetic abrasive polishing process for paramagnetic workpieces. A magnetic disc, which comprises six magnetic coils and is electrified with a three-phase AC current, is used to perform the experiments. In the experimental setup, various parameters including rotational speed of abrasive pins, quantity of abrasive pins, working gap, abrasive pins' dimensions, and process's time can be changed. Changing the surface quality of these parameters is investigated. Two kinds of workpieces with different mechanical properties are examined. It is observed that both increasing the rotational speed and using smaller pins improve the final surface quality; however, the rotational speed has a sharper effect. There are optimum abrasive pins quantity and working gap in which the best surface quality is obtained. The results are similar for the both selected materials.
\end{abstract}

(C) 2019 Sharif University of Technology. All rights reserved.

\section{Introduction}

Surface finish is one of the important stages in producing a part that can affect its performance and service life [1]. Magnetic Abrasive Finishing (MAF), which uses magnetic field as the driving force for surface finishing, is a way to produce desirable surface finish without surface damage [2]. In this process, a very small amount of material is separated by the movement of magnetic abrasive tools relative to the workpieces.

The MAF process was widely used to finish cylindrical [3,4] and flat workpieces [5-11]. The effectiveness of this process was also investigated in deburring of drilled holes located on planes [12].

MAF can be categorized with regard to the magnetic field type [13] including permanent magnet,

\footnotetext{
*. Corresponding author. Tel./Fax: +98 3133915227 E-mail address: rjafari@cc.iut.ac.ir (R. Jafari Nedoushan)
}

doi: $10.24200 /$ sci. 2018.20415 magnetic field produced by direct current, and magnetic field produced by alternating current.

Shinmura et al. [14] used Rotating Magnetic Field (RMF) obtained by alternating current to finish the inside of cylindrical workpieces. In their study, threephase AC current was used to electrify three coils and obtain RMF.

Based on the results of their experiments, while material removal is increased in the case where RMF is used, surface finish is reduced as compared to permanent magnetic field. They extended their work using six coils installed on a circular part [15]. The RMF was obtained by electrifying these coils via threephase AC current in this case, too. This process was used to finish the inside of stainless steel tube. In particular, this process was suggested for finishing of bent tubes' inside.

Yamaguchi et al. [16] proposed a method for controlling dynamic motion and applied force of the finishing tools. This process can be used to finish internal surface of products used in critical applications such as high-pressure piping systems. However, in 
these research studies, the effects of each parameter on the final product surface and optimum range of each parameters have not been studied comprehensively.

In the current paper, an experimental setup is designed and manufactured to investigate the effects of machining parameters of MAF with magnetic field produced by alternating current on the final products. This paper also investigates the optimum range of various process parameters.

\section{Materials and methods}

\subsection{Provided experimental setup}

The setup used for current experiments is shown in Figure 1. The main part of the setup is a magnetic disc, which comprises six magnetic coils. The coils are arranged on a circle with 60 degrees of distance, as shown in detail in Figure 2. RMF was obtained by electrifying the coils with the three-phase $\mathrm{AC}$ current.

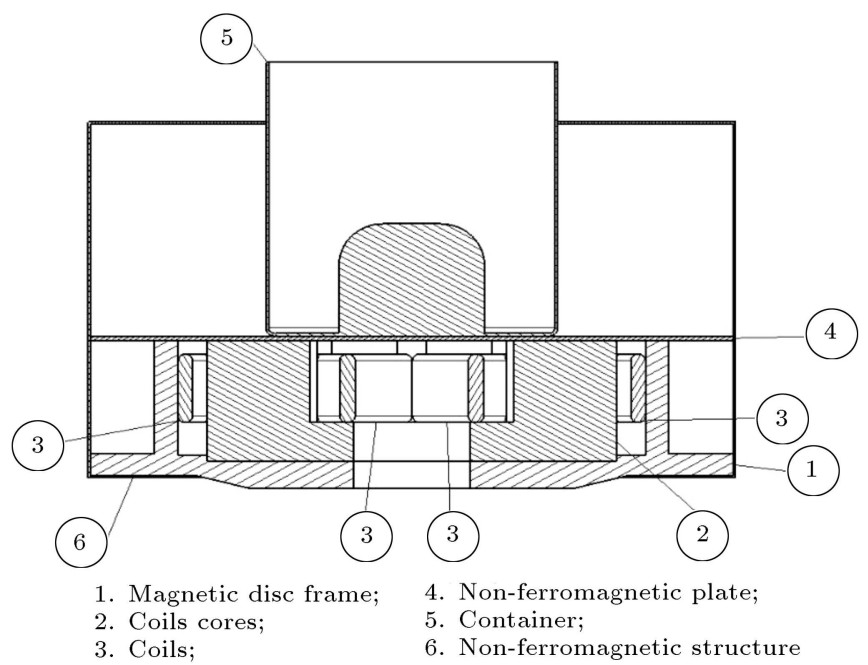

Figure 1. Details of designed experimental setup to obtain RMF.

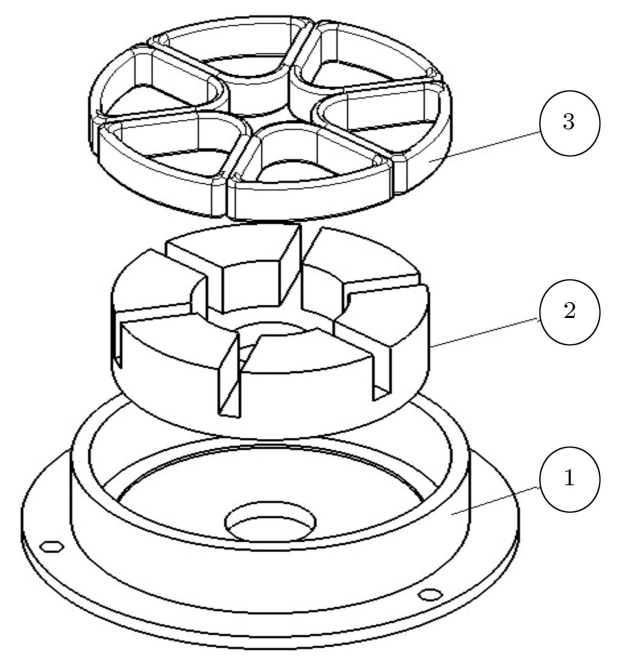

Figure 2. Magnetic disc assembly including magnetic disc frame, coils' cores, and coils.

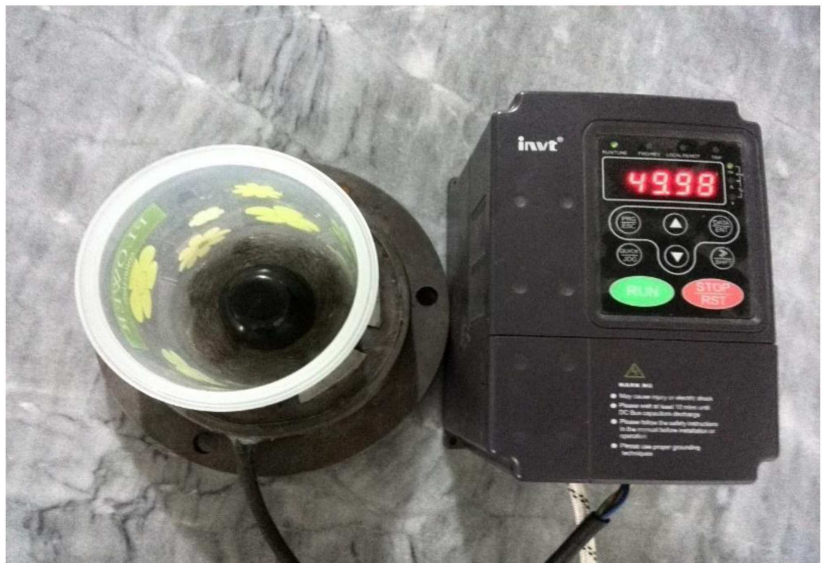

Figure 3. A view of the current experimental setup.

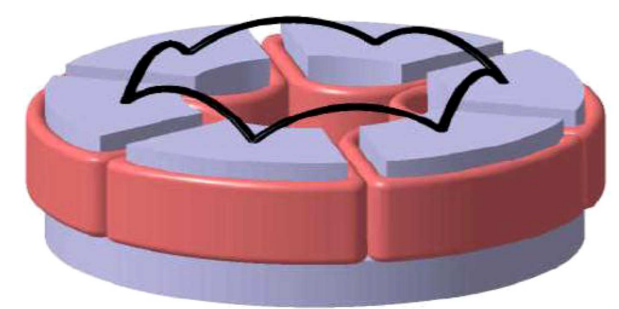

Figure 4. Path of the abrasive pins due to rotating magnetic field.

The design of the coils was done to generate a magnetic field intensity of 1.2 Tesla with voltage of $220 \mathrm{~V}$.

A cylindrical part containing workpieces, pinshaped magnetic abrasive parts, and water is located above the disc with a gap. Abrasive pins are made up of AISI 420 stainless steel (C: $0.15 \%, \mathrm{Si}: 1.00 \%, \mathrm{Mn}$ : $1.00 \%$, P: $0.04 \%$, S: $0.03 \%$, and Cr: $14.00 \%$ ).

RMF moves abrasive parts, resulting in debarring of the paramagnetic workpieces. Figure 3 shows the current experimental setup. Figure 4 shows the path of the abrasive pins due to the rotating magnetic field.

\subsection{Workpieces materials}

To evaluate the performance of the process on paramagnetic workpieces and investigate the effects of process parameters, two materials with different hardness degrees, including brass and aluminum, were selected. Mechanical properties of the mentioned materials are provided in Table 1.

Table 1. Mechanical properties of the selected materials.

\begin{tabular}{ccc}
\hline Material & $\begin{array}{c}\text { Yield stress } \\
\text { (MPa) }\end{array}$ & $\begin{array}{c}\text { Ultimate tensile } \\
\text { stress (MPa) }\end{array}$ \\
\hline AA-6061 & 145 & 240 \\
C85800 & 205 & 380 \\
\hline
\end{tabular}




\section{Results and discussion}

In this section, effects of process parameters including rotational speed of abrasive pins, abrasive pins' dimensions, abrasive pins' quantity, gap between the container and the coils, and deburring time on the final surface quality are investigated. At first, rotational speed of abrasive pins is investigated as a function of the current frequency, and the feasible range of rotational speeds is introduced.

\subsection{Rotational speed of abrasive pins}

Since AC current is used to produce a RMF in the provided setup, the process can easily be controlled by changing the current. Increasing current frequency will increase rotational speed of the magnetic field; however, this is not true all the time about the movement of the abrasive parts. Increasing current frequency also causes an increase in magnetic field strength; therefore, abrasive pins are absorbed into the container. It can be concluded that there is a current frequency value such that increasing frequency more than this limit will halt the process. On the other hand, at very low frequency, magnetic field strength is not sufficient to move abrasive pins.

Rotating speed of the magnetic field can be obtained by the frequency and number of poles. For two poles, the speed of the magnetic field is equal to the frequency rate; therefore, for $p$ poles, speed of the magnetic field can be calculated as follows:

$$
n s=\frac{120 * f}{p},
$$

where $n s$ is the speed of the magnetic field in RPM, $p$ is the magnetic poles number that is six here, and $f$ represents current frequency in $\mathrm{Hz}$. To compare predicted rotating speed of the magnetic field and actual speed of abrasive pins, abrasive pins' speed is measured by a laser speed measurement in various frequency rates. Figure 5 compares the speed of abrasives and magnetic field with the current frequency.

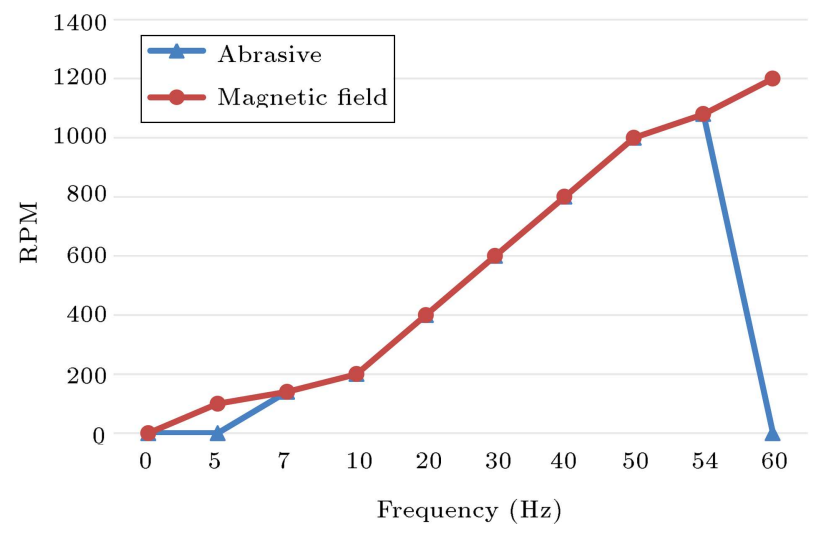

Figure 5. Rotational speed of abrasive pins and magnetic field versus current frequency.
As shown in Figure 5 in frequencies less than 5 $\mathrm{Hz}$, abrasive pins are motionless due to the weakness of the magnetic field. In frequencies more than $5 \mathrm{~Hz}$, increasing frequency increases the rotational speed of abrasive pins. This rule is true until frequency reaches $54 \mathrm{~Hz}$. At frequencies more than this value, abrasive pin will be absorbed into the container and do not move any longer. The maximum feasible frequency is $54 \mathrm{~Hz}$, which equals 1080 RPM based on Eq. (1).

\subsection{The effect of abrasive pins' rotational speed}

As discussed in the previous section, in the range of $5 \mathrm{~Hz}$ to $54 \mathrm{~Hz}$, increasing rotational speed of the magnetic field causes an increase in pins' speed. Figure 6 shows the effect of increasing frequency or consequently pins' speed on the final surfaces quality. Values of the other process parameters in these experiments are listed in Table 2, and the only difference is the current frequency. As is shown in this figure, by increasing frequency, $\mathrm{Ra}$ decreases for both of the materials; however, this effect is slightly more noticeable for the softer material (AA-6061). Averaged material removal of the best surface quality (maximum frequency) is listed in Table 3. However, in some researches, for low rotational speeds, an inverse effect was observed [7]. In this research, for rotational speeds close to the current paper, similar trends were observed, and the causes were explained.

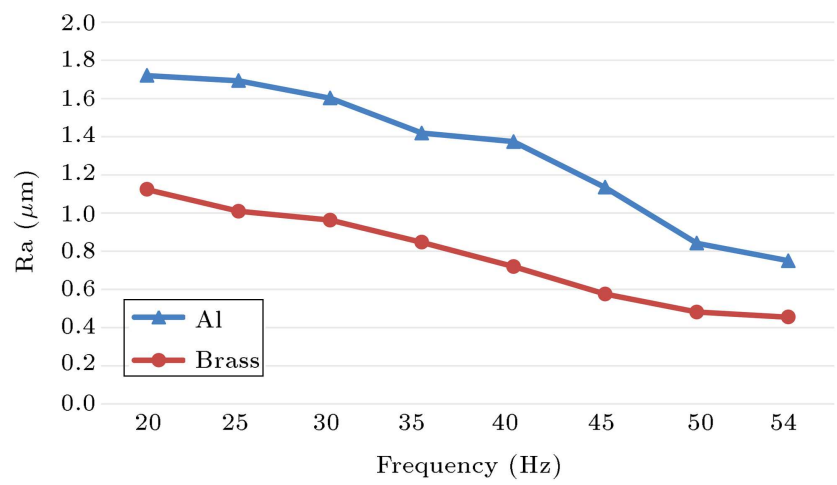

Figure 6. The effect of increasing frequency or, consequently, pins' speed on the product surface quality.

Table 2. Process's parameters for investigating the effect of pins' rotational speed.

\begin{tabular}{rc}
\hline Parameter & Value \\
\hline Process time & $35 \mathrm{~min}$
\end{tabular}

Pins dimensions:

$\begin{array}{lc}\text { Diameter } & 0.1 \mathrm{~mm} \\ \text { Length } & 1.5 \mathrm{~mm} \\ \text { Total weight } & 50 \mathrm{gr}\end{array}$

Gap between container and coils $1.5 \mathrm{~mm}$ 
Table 3. Averaged material removal for specimens.

\begin{tabular}{cccc}
\hline Material & $\begin{array}{c}\text { Mass before } \\
\text { debarring (gr) }\end{array}$ & $\begin{array}{c}\text { Mass after } \\
\text { debarring (gr) }\end{array}$ & $\begin{array}{c}\text { Reduction of } \\
\text { mass }\end{array}$ \\
\hline AA-6061 & 4.7296 & 4.7229 & $0.14 \%$ \\
C85800 & 0.5666 & 0.5602 & $1.13 \%$ \\
\hline
\end{tabular}

\subsection{The effect of abrasive pins' dimensions} To investigate the effect of pins' dimensions on the final surface quality, three different pins were used in the process. Examined pins' dimensions are listed in Table 4. Figure 7 shows the achieved surface quality for all the pins. Other circumstances of these experiments are shown in Table 5. It can be concluded from Figure 6 that in the investigated range of pins' dimensions, better surface quality can be obtained with smaller pins for both materials. However, the effect of pins' dimensions is lower than that of other parameters. It has been reported that the increasing number of cutting edges of the abrasives available in a smaller area does not improve the surface finish in plane MAF process [17].

Averaged material removal for the optimum pins' dimension is listed in Table 6 .

\subsection{The effect of abrasive pins' quantity}

Figure 8 shows the effect of pins' quantity on product surface quality. In this case, there is an optimum point at which the best surface quality is obtained. The excessive increase of pins' number leads to a stronger contact between pins and reduces the contact between

Table 4. Examined pins' dimensions.

\begin{tabular}{ccc}
\hline $\begin{array}{c}\text { Experiment } \\
\text { number }\end{array}$ & $\begin{array}{c}\text { Pins length } \\
(\mathbf{m m})\end{array}$ & $\begin{array}{c}\text { Pins diameter } \\
(\mathbf{m m})\end{array}$ \\
\hline 1 & 1.5 & 0.1 \\
2 & 2.7 & 0.5 \\
3 & 5 & 1.2 \\
\hline
\end{tabular}

Table 5. Process's parameters for investigating effect of pins' dimensions.

\begin{tabular}{cc}
\hline Parameter & Value \\
\hline Process time & $35 \mathrm{~min}$ \\
Gap between container and coils & $1.5 \mathrm{~mm}$ \\
Current frequency & $50 \mathrm{~Hz}$ \\
\hline
\end{tabular}

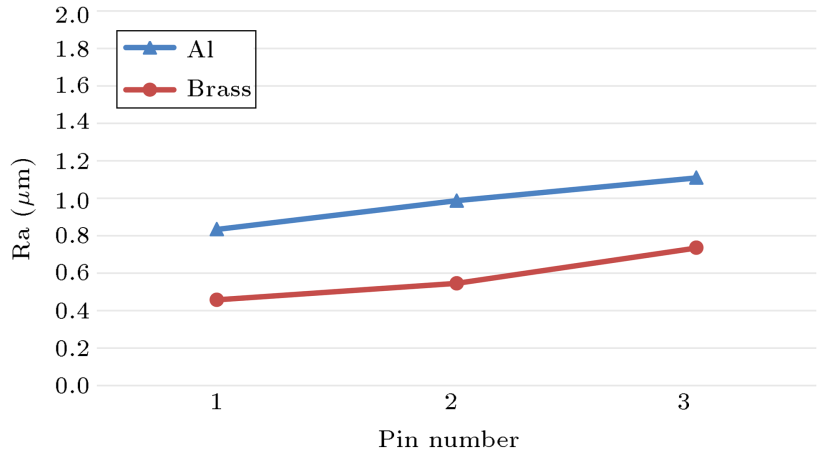

Figure 7. The effect of pins' dimensions on product surface quality.

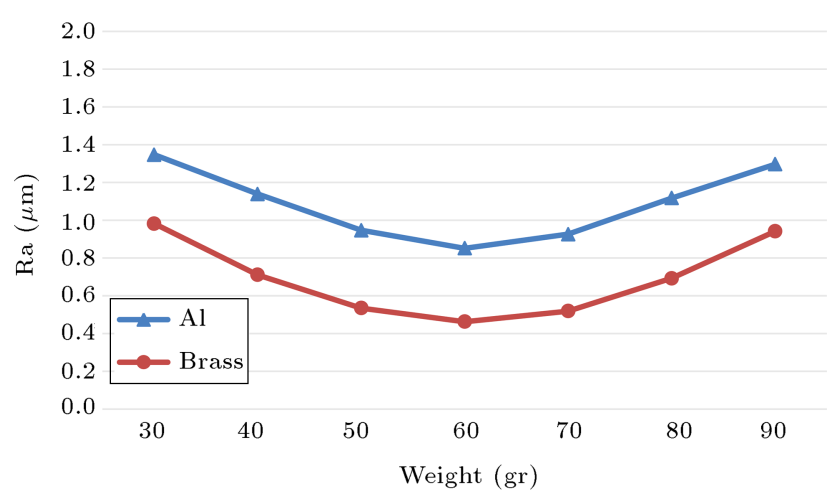

Figure 8. The effect of pins' quantity on product surface quality.

pins and workpieces; consequently, efficiency of the process decreases. On the other hand, it is obvious that reducing pins' number too much will reduce the effectiveness of the process. As is explained by [7], as the percentage weight of the abrasive increases, the cutting edges available for cutting the peaks of the surface texture multiply. This may improve the surface finish. In these experiments, parameters of the process are the same as those reported in Table 5. Averaged material removal for the optimum pins' quantity is listed in Table 7.

Table 6. Averaged material removal for the optimum pins' dimension.

\begin{tabular}{cccc}
\hline Material & $\begin{array}{c}\text { Mass before } \\
\text { debarring (gr) }\end{array}$ & $\begin{array}{c}\text { Mass after } \\
\text { debarring (gr) }\end{array}$ & $\begin{array}{c}\text { Reduction of } \\
\text { mass }\end{array}$ \\
\hline AA-6061 & 4.7383 & 4.7317 & $0.14 \%$ \\
C85800 & 0.5673 & 0.5581 & $1.62 \%$ \\
\hline
\end{tabular}


Table 7. Averaged material removal for the optimum pins' quantity.

\begin{tabular}{cccc}
\hline Material & $\begin{array}{c}\text { Mass before } \\
\text { debarring (gr) }\end{array}$ & $\begin{array}{c}\text { Mass after } \\
\text { debarring (gr) }\end{array}$ & $\begin{array}{c}\text { Reduction of } \\
\text { mass }\end{array}$ \\
\hline AA-6061 & 4.7251 & 4.7164 & $0.18 \%$ \\
C85800 & 0.5743 & 0.5706 & $0.64 \%$ \\
\hline
\end{tabular}

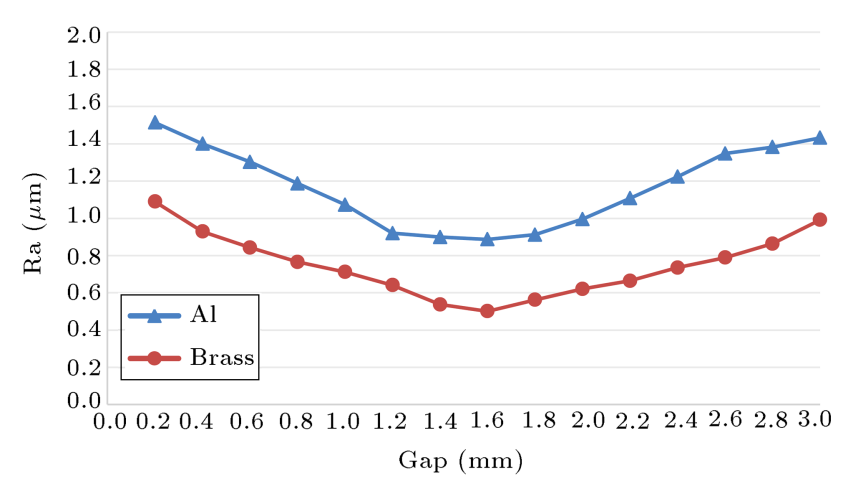

Figure 9. The effect of the gap between the container and the coils on product surface quality.

\subsection{The effect of gap between the container and the coils}

One of the parameters that affects the final surface quality is the gap between the container and the coils. This effect corresponds to the dependence of the magnetic field strength on this gap. As can be observed in Figure 9, the best surface quality can be achieved by setting this gap as $1.6 \mathrm{~mm}$. In distances less than this value, the intensity of the magnetic field causes pins to attach to the container; consequently, their rotational speed will reduce. As discussed in Section 3.2, reducing pins' rotational speed will result in a low surface quality. In distances more than $1.6 \mathrm{~mm}$, pins' speed is reduced due to the weakness of the magnetic field and its gradient. Values of the other process parameters in these experiments are the same as the data in Table 5. Averaged material removal for the best surface quality in these experiments is listed in Table 8.

\subsection{The effect of deburring time}

As expected, as the process continues for a longer time, the resulted surface quality is more desirable. However, under the current circumstances, increasing the deburring time more than 35 min leads to no significant changes in the results, as observed in Figure 10.

It is in contrast with results of Mulik and

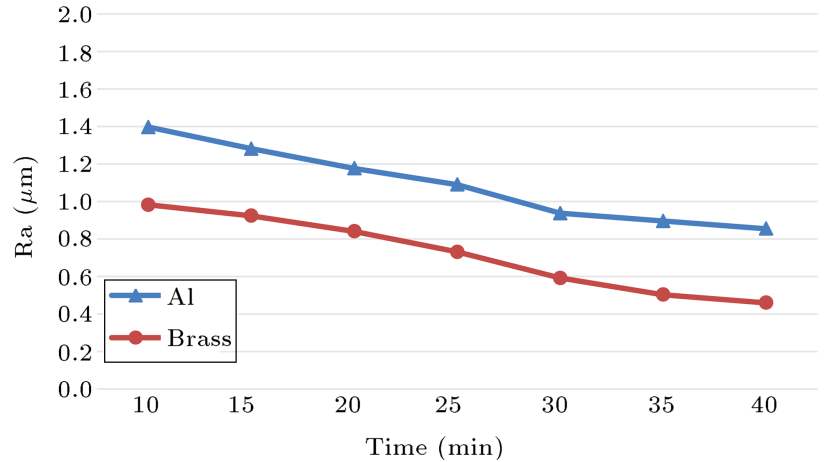

Figure 10. The effect of deburring time on product surface quality.

Pandey [7] such that after a definite finishing time, surface roughness starts increasing. This is because in their research, $\mathrm{SiC}$ grains, which are very hard, friable, and brittle, were used. SiC particles were fractured, and many sharp cutting edges were formed. However, in the current work, the shape of abrasive points does not change during the process.

Figure 11 compares the initial workpieces and the deburred ones with the best obtained surface quality. As it can be seen from this figure, while the burs in the final parts are omitted, the geometry remains unchanged.

By comparing Figures 6-10, it can be concluded that the abrasive pins' speed, which directly depends on the current frequency, has slightly stronger effect on the surface finish.

\section{Conclusions}

This study investigated deburring and polishing of paramagnetic workpieces by ferromagnetic abrasive parts, which were moved by a magnetic field. The results showed significant improvement in the surface quality without changing the workpiece's geometry. Investigation of the effects of various parameters on the process showed that:

Table 8. Averaged material removal for the optimum gap.

\begin{tabular}{cccc}
\hline Material & $\begin{array}{c}\text { Mass before } \\
\text { debarring (gr) }\end{array}$ & $\begin{array}{c}\text { Mass after } \\
\text { debarring (gr) }\end{array}$ & $\begin{array}{c}\text { Reduction of } \\
\text { mass }\end{array}$ \\
\hline AA-6061 & 4.7437 & 4.7332 & $2.2 \%$ \\
C85800 & 0.5793 & 0.5738 & $0.94 \%$ \\
\hline
\end{tabular}




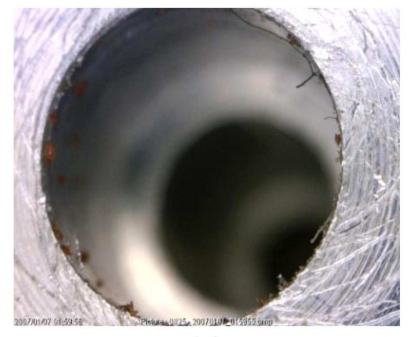

(a)

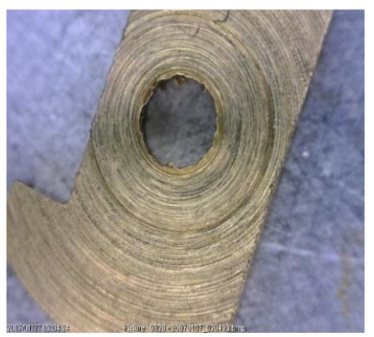

(c)

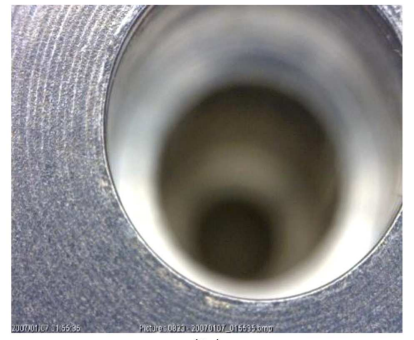

(b)

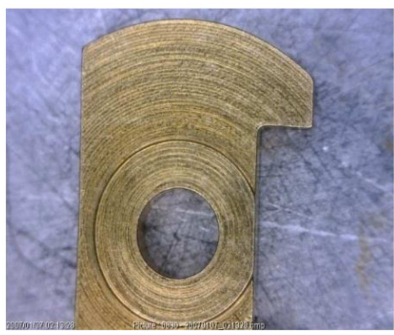

(d)
Figure 11. A view of the initial and deburred workpieces: (a) Initial Al workpiece, (b) deburred Al workpiece, (c) initial brass workpiece, and (d) deburred brass workpiece.

- Increasing the rotational speed improved the final surface quality;

- Abrasive pins' dimensions had significant effect on the final surface; in the current case, smaller pins resulted in better surface quality;

- There was an optimum abrasive pins quantity in which the best surface quality was obtained;

- There was also an optimum gap between the workpieces' container and the magnetic coils;

- The results of trends of the selected materials were similar; however, the softer material showed more sensitivity in some cases.

\section{References}

1. Kenton, T. "The future of mechanical surface finishing", Met Finish, 107(5), pp. 22-26 (2009).

2. Jain, V.K. "Magnetic field assisted abrasive based micro-nano-finishing", Mater. Process. Technol., 209(20), p. 209 (2009).

3. Fox, M., Agrawal, K., Shinmura, T., and Komanduri, R. "Magnetic abrasive finishing of rollers", CIRP Ann Manuf. Technol., 43(1), pp. 181-185 (1994).

4. Yamaguchi, H., Shinmura, T., and Raghuram, V. "Study of an internal magnetic abrasive finishing using a pole rotation system. Discussion of the characteristic abrasive behaviour", Int. J Adv Manuf. Technol., 24, pp. 237-244 (2000).

5. Jain, V.K., Singh, D.K., and Raghuram, V. "Analysis of performance of pulsating flexiblemagnetic abrasive brush (P-Fmab)", Mach. Sci. Technol., 12(1), pp. 5376 (2008).
6. Yin, S. and Shinmura, T. "A comparative study: polishing characteristics and its mechanisms of three vibration modes in vibration-assisted magnetic abrasive polishing", Int J Mach Tools Manuf, 44(4), pp. 383-390 (2004).

7. Mulik, R.S. and Pandey, P.M. "Ultrasonic assisted magnetic abrasive finishing of hardened AISI 52100 steel using unbonded SiC abrasives", Int J Refract Met Hard Mater, 29(1), pp. 68-77 (2011).

8. Mulik, R.S. and Pandey, P.M. "Experimental investigations and modeling of finishing force and torque in ultrasonic assisted magnetic abrasive finishing", $J$ Manuf Sci Engm ASME, 5(134), pp. 1-12 (2012).

9. Mulik, R.S., Srivastava, V., and Pandey, P.M. "Experimental investigations and modeling of temperature in the work-brush interface during ultrasonic assisted magnetic abrasive finishing process", Materials and Manufacturing Processes, 27(1), pp. 1-9 (2012).

10. Mishra, V., Goel, H., Mulik, R.S., and Pandey, P.M. "Determining work-brush interface temperature in magnetic abrasive finishing process", Journal of Manufacturing Processes, 16(2), pp. 248-256 (2014).

11. Kim, T. and Kwak, J. "A study on deburring of magnesium alloy plate by magnetic abrasive polishing", International Journal of Precision Engineering and Manufacturing, 11(2), pp. 189-194 (2006).

12. Baron, Y.M., Ko, S.L., and Park, J.I., "Characterization of the Magnetic Abrasive Finishing Method and Its Application to Deburring", Key Engineering Materials, pp. 291-296 (2005).

13. Kumar, H., Singh, S., and Kumar, P. "Magnetic abrasive finishing- a review", International Journal of Engineering Research \& Technology, 2(3), pp. 1-9 (2013).

https://www.ijert.org/volume-02-issue-03-march-2013

14. Shinmura, T., Hatano, E., and Takazawa, K. "The development of magnetic abrasive finishing and its equipment by applying a rotating magnetic field", Bulletin Japan Society of Mechanical Engineering, 29(258), pp. 4437-4443 (1986).

15. Shinmura, T., Yamaguchi, H., and Shinbo, Y. "A new internal finishing process of a non-ferromagnetic tubing by applying a rotating magnetic field", Precision Engineering, 26(4), pp. 302-304 (1992).

16. Yamaguchi, H., Shinmura, T., and Takenaga, M. "Development of a new precision internal machining process using an alternating magnetic field", Precision Engineering, 27, pp. 51-58 (2003).

17. Girma, B., Joshi, S.S., Raghuram, M.V.G.S., and Balasubramaniam, R. "An experimental analysis of magnetic abrasives finishing of plane surfaces", Mach Sci Technol, 10(3), pp. 323-40 (2006).

\section{Biographies}

Seyed Mohsen Safavi is a Faculty Member of Isfahan University of Technology and is currently working as an 
Associate Professor at the Department of Mechanical Engineering. He was born in 1959 and pursued his BSc degree in Mechanical Engineering majoring in Design and Manufacturing at University of Tehran and Isfahan University of Technology where he graduated in 1985 . He continued his higher education on Scholarship in the same major for MSc and PhD at George Washington University in 1987 and University of Maryland in 1991, respectively. $\mathrm{He}$ is the author of 85 journal and conference papers and, also, the author of 14 books in his research fields in Mechanical Engineering concentrating on manufacturing systems, CIM, automation, CNC, robotics, jig and fixture design, automatic assembly and product design.
Sajjad Hasanvand obtained his BS degree in Mechanical Engineering from Mohajer Technical University of Isfahan, Isfahan, Iran in 2013 and his MS degree from Isfahan University of Technology, Isfahan, Iran in 2016.

Reza Jafari Nedoushan received BS, MS, and PhD degrees in Mechanical Engineering from Isfahan University of Technology, Isfahan, Iran in 2005, 2008, and 2012, respectively. He is currently an Assistant Professor at Isfahan University of Technology, Isfahan, Iran. His research interests include meso-macro modeling of textile composites and preforms and novel composite structures. 